\title{
Hanoman Obong sebagai Ide Kreatif Penciptaan Night Light Shadow Box
}

\section{Hanoman Obong as A Creative Idea of Creation Night Light Shadow Box}

\author{
Aqim Amral Hukmi \\ Madrasah Aliyah Ibadurrohman, Malang, Indonesia
}

\begin{abstract}
Abstrak
Pewayangan merupakan suatu kebudayaan bangsa Indonesia. Cerita pewayangan awalnya berkembang pada jaman Hindu Jawa. Pewayangan telah diangkat sebagai suatu karya agung budaya dunia oleh UNESCO tanggal 7 Nopember 2003 atau Masterpiece of Oral and Intangible Heritage of Humanity. Salah satu tokoh yang tidak asing dalam cerita pewayangan adalah Hanoman. Namun, saat ini masyarakat terutama remaja yang menyebut dirinya milenial kurang tertarik dengan cerita pewayangan. Untuk mengenalkan kebudayaan tradisional kepada masyarakat dan remaja milenial sebagai generasi muda membutuhkan terobosan atau cara baru yang inovatif, termasuk media populer di kalangan anak muda, termasuk menciptakan lampu dekorasi interior yang disebut Night Light Shadow Box. Metode penelitian yang digunakan adalah metode penelitian kualitatif deskirptif. Penelitian dimulai dengan mengeksplorasi figur Hanoman. Selanjutnya mengembangkan hasil observasi yang telah dilakukan melalui desain produk Night Light Shadow Box sehingga menghasilkan produk kreatif yang sesuai dengan minat masyarakat dan remaja milenial. Tujuan dari penelitian ini, (1) untuk menciptakan produk kreatif bervisi muatan lokal Hanoman yang dapat bersaing dengan prodak asing. (2) dapat menumbuhkan pemahaman dan cinta masyarakat terhadap budaya lokal nusantara. Kata Kunci: Pewayangan; Hanoman Obong; Night Light Sadow Box
\end{abstract}

\section{Abstract}

Puppet is a culture of the Indonesian nation. Puppet stories originally developed during the Javanese Hindu era. Pewayangan has been appointed as a masterpiece of world culture by UNESCO on 7 November 2003 or the Masterpiece of Oral and Intangible Heritage of Humanity. One of the familiar characters in puppet stories is Hanoman. However, nowadays people, especially teenagers who call themselves millennials, are less interested in puppet stories. To introduce traditional culture to society and millennial adolescents as the younger generation, breakthroughs or new innovative ways are needed, one of which is media that is popular among young people, namely by making a room decoration lamp called the Night Light Shadow Box. The research method used is descriptive qualitative research methods. The research begins by exploring the Hanoman figure. Furthermore, developing the results of observations that have been made through the product design of the Night Light Shadow Box so as to produce creative products that are in accordance with the interests of the community and millennial youth. The purpose of this research is (1) to create creative products with Hanoman local content vision that can compete with foreign products. (2) can foster understanding and love of the community towards the local culture of the archipelago.

Keywords: Puppetry; Hanoman Obong; Night Light Sadow Box

How to Cite: Hukmi, A.A. (2021) Hanoman Obong sebagai Ide Kreatif Penciptaan Night Light Shadow Box. Jurnal Pendidikan dan Penciptaan Seni, 1(2) 2021: 78-89 


\section{PENDAHULUAN}

Indonesia merupakan suatu negara yang memiliki kebudayaan tradisional yang beragam. Kebudayaan tradisional merupakan sebuah aset bangsa yang sangat berharga dalam menjawab tantangan kebutuhan dunia saat ini. Salah satu kebudayaan yang mungkin tidak asing adalah cerita pewayangan. Pewayangan pernah mengalami masa kejawayaan di masa lampau. Kebudayaan tersebut mampu mengumpulkan dan menyampaikan nilai-nilai moral kepada masyarakat.

Sejarah wayang berkembang dari zaman Hindu Jawa. Hanoman adalah salah satu dari sedikit tokoh pewayangan yang mudah dikenali karena bentuknya seperti kera putih, anak dari Batara Guru dan Anjani. Hanoman adalah tokoh wayang yang penokohannya menyimpang dari kaidah wayang. Wayang biasanya digambarkan dengan wajah tegap, mata kecil, wajah menunduk, dan mulut tertutup (Solichudin, 2016). Menurut Zulkarnain dalam (Solichudin, 2016) bahwa Hanuman adalah sosok yang rendah hati, pemberani, sopan, setia, tahu harga diri, memiliki kesaktian tinggi dan sifat-sifat lain yang mencerminkan sosok ksatria, digambarkan dengan mata melotot, wajah terangkat (mewakili kesombongan) dan mulut dengan gigi besar. dan buka.

Namun, saat ini mulai sulit ditemukan orang yang masih mengetahui tentang sejarah dan kebudayaan seperti cerita pewayangan Hanoman dikarenakan kurang menariknya kebudayaan masa lalu diakibatkan masuknya pengaruh kebudayaan asing sehingga menggeser keberadaan kebudayaan tradisional pada masyarakat dan remaja milenial. Perlunya sebuah inovasi baru dalam melestarikan kebudayaan tradisional melalui sebuah produk yang dapat bersaing dengan produk asing. Produk yang dapat mewakili sebuah tokoh pewayangan karena memiliki karakter figure yang mudah dikenali.

Hanoman memiliki karakter yang kuat, keunikan fisik seperti bulu putih dan keberaniannya dalam setiap cerita Ramayana yang membuatnya mudah dikenali dibandingkan dengan karakter Ramayana lainnya. Hal inilah yang mengilhami ide-ide kreatif untuk berkreasi, yaitu berani, bertanggung jawab, kuat dan bijaksana sehingga disegani kawan dan lawan. Bentuk karakter figur hanoman tersebut kemudian diekspresikan ke dalam produk karya lampu hiasan ruangan "Night Light Sadow Box." Sebelum melangkah lebih jauh, ada beberapa penelitian sebelumnya yang memiliki persamaan dengan penelitian ini. Ini berkaitan dengan pelestarian budaya dengan ide kreatif berupa "Desain Calongcong" yang terbukti efektif sebagai upaya pelestarian budaya kerajinan tradisional, karena kandungan makna-makna dan nilai luhung di dalamnya (Alif, Savitri and Emilda, 2018). Demikian pula karya-karya keramik karya Giyono banyak mengandung nilai semiotik berupa pesan dan makna yang dihadirkan melalui bentuk-bentuk yang ada dalam karya, serta ungkapan-ungkapan pengarang yang berusaha ditempatkan dalam karya seni tersebut (Subandi, 2017). Selanjutnya terdapat penelitian sejenis yang menjelaskan pelestarian budaya cerita Ramayana dalam bentuk permainan kartu yang terbukti efektif untuk memperkenalkan tokoh-tokoh pewayangan dari kisah Ramayana (Sebastian et al., 2017).

Tujuan khusus yang hendak dicapai dalam penelitian ini adalah. (1) Menghasilkan konsep desain lampu hiasan ruangan "Night Light Sadow Box" bervisi budaya lokal Hanoman. (2) Menghasilkan metode yang diterapkan dalam proses kreatif mengolah potensi cerita pewayangan karakter Hanoman menjadi sebuah lampu hiasan ruangan "Night Light Sadow Box.

\section{METODE PENELITIAN}

Metode penelitian menggunakan diskripsi kualitatif, Menurut Denzin dan Licolnatkan (2009). Dalam pendekatan ini, penelitian menekankan sifat realitas yang dibangun secara sosial, hubungan erat yang terjalin antara peneliti dan sumber yang diteliti.Penelitian kualitatif berlangsung dalam kondisi alami dan terbuka. (Noor, 2015). Penelitian kualitatif berusaha menjelaskan secara deskriptif hasil dari pengambilan data dan pengumpulan data. Data terkumpul dengan teknik wawancara dan observasi lapangan. Kemudian setelah lengkap maka data tersebut di olah dan dianalisis sehingga membentuk sebuah teks naratif. 
Adapaun bagan dalam proses penciptaan adalah sebagi berikut:



Gambar 1. Bagan Proses Penciptaan Sumber: Dokumntasi Pibadi

Bagan tersebut meneggambarkan bagaimana tahapan peneltian ini sehingga tercita sebuah karya dari ide kreatif. Melalui beberapa tahapan proses penciptaan yang diawali dengan proses mencari ide dan direnungkan. Setelah perenungan maka masuk tahap pengolahan ide tersebut menjadi rangangan desain awal atau pra desain. Selanjutnya adalah memilih desain terbaik dan masuk rancangan final. maka terciptalah sebuah produk karya seni lampu hiasan ruangan "Night Light Sadow Box" yang layak untuk dinikmati oleh masyarakat dan dipublikasikan.

\section{HASIL DAN PEMBAHASAN}

\section{Legenda Pewayangan Hanoman}

Wayang adalah kesenian orisinil Indonesia yang sudah diresmikan menjadi Warisan Budaya Dunia/Internasional dari tahun 2003 sang UNESCO, jauh sebelum Batik, Keris \& Angklung dipatenkan. Oleh lantaran itu, Indonesia mempunyai kewajiban buat melestarikan mata budaya tersebut. Hingga ketika ini, cerita wayang belum sebagai budaya yang terpelihara menggunakan baik pada warga Indonesia (Solichudin, 2016).

Salah satu cerita wayang yang terkenal adalah cerita Hanoman. Hanuman sendiri adalah kera putih dengan kekuatan magis. Hanuman sendiri adalah kera putih dengan kekuatan magis. Hanuman sendiri adalah anak dari Dewi Anjani dan Batara Guru. Perjalanan Hanoman ke Alengka ditandai dengan berbagai konflik dan pertempuran. Dalam cerita wayang Hanoman Obong, masih banyak tokoh pewayangan lainnya. Di antaranya adalah Jatayu, seekor burung raksasa yang membantu Hanoman mengambil Sinta. Kehadiran Hanoman di Alengka tentu membuat marah Prabu Dasamuka. Hanuman sengaja membiarkan dirinya ditangkap.Raja Dasamuka yang marah 
kemudian memerintahkan pasukannya untuk membakar Hanoman hidup-hidup (Solichudin, 2016).

Melihat hal itu, Sinta berdoa agar arang yang membakar ekor Hanoman menjadi dingin. Ketika doa Sinta kepada Dewa Agni dikabulkan, bara api dari ekor Hanuman mendingin. Kemudian dia memberontak dan melepaskan Brahma Astra yang mengikatnya. Kota Alengka Kota Alengka menyerupai laut barat. Setelah menyalakan api besar, lompat ke laut untuk memadamkan api di ekornya. Penghuni Langit memuji keberanian Hanoman dan mengungkapkan bahwa di luar kediaman Sinta, kota Alengka dilalap api. Membawa informasi gembira, Hanoman pergi ke Rama dan memberitahu dia tentang keadaan Shinta. Rama kemudian mempersiapkan pasukan Vanara untuk menyerang Alengka. (Yusa, 2016).

Setelah berakhirnya pertempuran besar melawan Rahwana, Rama ingin memberikan hadiah kepada Hanoman, tetapi Hanoman menolak karena dia hanya ingin Sri Rama bersemayam di hatinya..(Yusa, 2016).

\section{Kajian Karakter dan Nilai Moral Hanoman}

Hanuman artinya salah satu tokoh yang unik karena berbentuk seperti kera putih serta berperan penting pada cerita Ramayana. Dipilihnya Hanoman menjadi tokoh sentral pada merealisasikan pertanyaan ini dikarenakan sifat atau karakter Hanoman yang berbeda dengan tokoh-tokoh pewayangan lain yang umum dikenal warga. Hanoman artinya salah satu tokoh pewayangan yang penokohannya menyimpang dari kaidah wayang. Representasi tokoh yang mempunyai watak kesatria pada wayang umumnya digambarkan menggunakan paras yang tegap, mata yang kecil, paras yang menunduk serta lisan yang tertutup. Sedangkan Hanuman yang rendah hati, pemberani , sopan, setia, memahami harga diri, mempunyai kesaktian tinggi dan sifat-sifat lain yang mencerminkan sosok ksatria digambarkan menggunakan mata melotot, wajah terangkat (mewakili kesombongan) dan mulut menggunakan gigi tajam, besar serta terbuka (Solichudin, 2016). Karakter inilah yang menjadi ciri khas Hanoman, sehingga penulis memilih cerita Hanoman sebagai dasar dari pembuatan produk karya lampu hiasan ruangan "Night Light Sadow Box".

Karakter Hanoman dianggap mampu menjadi icon atau trademark yang dapat mewakili budaya Indonesia. Ikon adalah benda fisik yang menyerupai apa yang dipresentasikannya (Wulandari and Siregar, 2020). Contoh penjelmaannya adalah maskot Taman Mini Indonesia Indah bernama Nitra atau Anjani Putra yang diresmikan oleh ibunda Tien Suharto pada tahun 1990. Maskot Hanoman merupakan simbol yang mewakili keragaman budaya Indonesia di TMII. Hanoman juga menjadi maskot Sea Games 2007 yang berlangsung di Jakarta. Selain itu, Hanoman adalah karakter yang menarik minat orang asing baik dalam pertunjukan balet maupun wayang. Dalam satu kasus di Bali, bayangan Cina Hanuman sangat menarik bagi wisatawan asing, terutama Jerman, Prancis, dan Australia.

Secara moral, cerita Hanoman menyampaikan pesan bahwa kita tidak boleh melihat seseorang hanya dari penampilan fisiknya, meskipun berwujud kera, tetapi Hanoman memiliki jiwa sosial dan kesatria yang tinggi dan siap mengorbankan dirinya. pesannya adalah kita harus selalu ikhlas membantu orang lain yang sedang kesulitan. Kebudayaan di Indonesia memiliki nilainilai yang berbeda yang tercermin dalam seni yang ada dalam bidang tertentu karena seni tersebut berasal dari latar belakang sosial budaya penciptanya (seniman) yang memiliki nilai estetika tersendiri Budaya seni tradisional pada zaman modern ini, tampaknya masyarakat mulai mengabaikan budaya masyarakatnya sendiri (Kristanto, 2017).

Pengetahuan seni dan budaya tradisional lokal mengandung nilai-nilai luhur Bangsa dan kearifan lokal yang sangat bernilai dalam pembentukan karakter bangsa. (Daniah, 2016). Kearifan lokal merupakan produk budaya masa lalu yang terus dijadikan pedoman hidup, walaupun memiliki nilai lokal tetapi nilai yang dikandungnya dianggap sangat universal. (Njatrijani, 2018). Agar nilai-nilai luhur dan kearifan lokal dapat diwariskan kepada masyarakat global dari generasi ke generasi, diperlukan upaya untuk menyebarluaskan nilai-nilai luhur bangsa dan kearifan lokal dalam pengetahuan seni dan budaya tradisional lokal kepada masyarakat. masyarakat. Komunitas dengan pendekatan yang relevan saat ini melakukan transfer media tanpa mengorbankan nilainilai yang sebenarnya. Tujuan dari transfer media adalah untuk lebih menarik khalayak yang 
berbeda tanpa batas kelas, serta membuatnya lebih mudah diakses untuk memenuhi kebutuhan masyarakat.

Untuk itu melalui penciptaan produk seni lampu hiasan ruangan "Night Light Sadow Box", mampu mengajak masyarakat untuk memiliki pengetahuan kesenian dan budaya lokal tradisional. Melalui karya seni Hanoman yang digunakan sebagai sumber inspirasi penciptaan sebuah produk karya seni yang sesuai dengan perkembangan zaman.

Target pemasaran dari produk ini adalah para masyarakat dan remaja milenial yang datang berkunjung destinasi wisata lokal baik anak-anak hingga orang remaja milenial. Mereka akan tertarik dengan produk karya seni lampu hiasan ruangan "Night Light Sadow Box" bervisi budaya lokal karakter figur Hanoman yang dirancang dengan model baru yang lebih menarik sehingga mulai anak-anak hingga remaja-remaja milenial tertarik dengan produk tersebut.

\section{Penciptaan Karya}

Ide Penciptaan.Penciptaan adalah suatu peristiwa yang merupakan proses bertahap, yang diawali dengan munculnya suatu dorongan hati yang dialami oleh seorang seniman (Mulyadika and Lodra, 2018). Seorang seniman sangat peka dalam menyikapi kondisi yang ada di lingkungannya, hal ini dapat dipengaruhi oleh berbagai faktor, yaitu faktor yang berasal dari dalam dirinya sendiri atau faktor yang berasal dari dalam dirinya sendiri. di dalamnya terdapat hati nurani yang kuat dan keinginan untuk menciptakan suatu karya berdasarkan pengetahuan, keahlian, dan pengalaman estetisnya. Sedangkan faktor eksternal adalah kepekaan mereka untuk merefleksikan keadaan atau peristiwa yang terjadi di lingkungan alam mereka, yang kemudian menjadi sumber ide-ide kreatif. (Andeska, 2018).

Lingkungan. Masyarakat saat ini mulai tidak mengenali dengan kebudayaan lokal yang ada di daerahnya. Mereka lebih mengenal kebudayaan yang datang dari luar. Melihat pentingnya untuk melestarikan budaya lokal dan menguatkan pengetahuan mereka tentang kebudayaan lokal nusantara, maka saat ini perlu dibuat sebuah produk yang dapat menyesuaikan dengan perkembangan zaman tanpa meninggalkan kebudayaan lokal nusantara, yaitu produk karya seni lampu hiasan ruangan "Night Light Sadow Box" yang bervisi budaya lokal karakter Hanoman.

Karkter Hanoman. Karakter hanoman sebagai sebuah figure yang menonjol dalam cerita pewayangan karena memiliki keunikan tersendiri dari karakter yang lain. Hal ini berkaitan dengan bentuk tubuh yang menyerupai kera dan manusia dengan bulu putih. Maka membuat seniman dalam hal ini peneliti ingin membuat sebuah karya dengan sumber ide penciptaan karakter Hanoman sehingga membentuk produk baru yaitu produk karya seni lampu hiasan ruangan "Night Light Sadow Box" yang bervisi budaya lokal karakter Hanoman.

Persiapan Alat dan Bahan. Proses pembuatan suatu karya pasti membutuhkan sebuah alat dan bahan yang akan digunakan dalam proses berkarya. Maka alat dan bahan haruslah dipersiapkan terlebih dahulu sehingga mempermudah dalam proses berkarya. Berikut alat serta bahan yang digunakan dalam proses pembuatan produk karya seni lampu hiasan ruangan "Night Light Sadow Box".

Alat: Pensil, Palu, Gergaji, Gunting dan Cutter

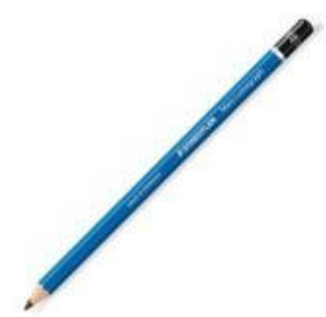

Gambar 2. Pensil

Sumber: Dokumentasi Internet

Pensil berfungsi untuk membuat pola desain produk karya seni lampu hiasan ruangan "Night Light Sadow Box" 
Aqim Amral Hukmi, Hanoman Obong sebagai Ide Kreatif Penciptaan Night Light Shadow Box

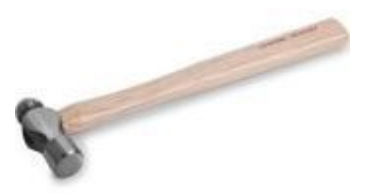

Gambar 3. Palu

Sumber: Dokumentasi Internet

Palu berfungsi untuk menyatukan kayu sehingga terbentuk sebuah pigora

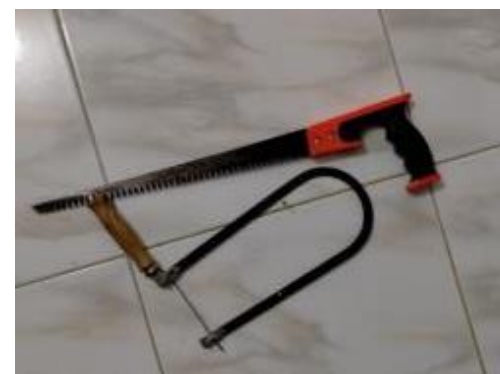

Gambar 4. Gergaji

Sumber: Dokumentasi Pribadi

Gergaji berfungsi untuk memotong kayu dalam membuatan produk karya seni lampu hiasan ruangan "Night Light Sadow Box"

Gambar 5. Gunting dan Kater

Sumber: Dokumentasi Pribadi

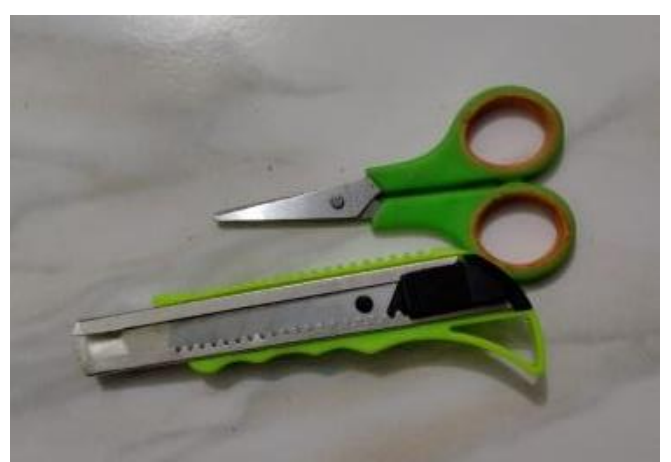

Gunting dan Kater berfungsi sebagai alat untuk memotong kertas AP 310 pada pembuatan produk karya seni lampu hiasan ruangan "Night Light Sadow Box" 
Bahan: Kertas AP 310, Kayu, Paku, Lampu LED, Akrilic

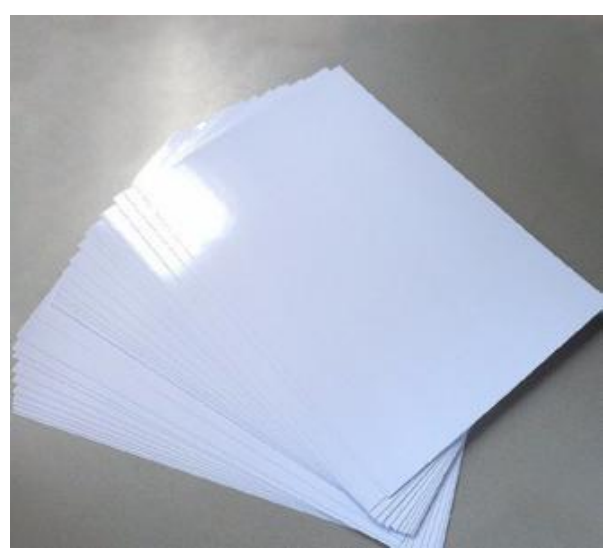

Gambar 3. Kertas AP 310

Sumber: Dokumentasi Internet

Kertas AP 310 berfungsi untuk layer pada produk karya seni lampu hiasan ruangan "Night Light Sadow Box". Pemilihan kertas AP karena miliki kesan glossy dan dengan ketebalan 310 akan memudahkan dalam membuat layer dalam karya tersebut.

$$
\text { Gambar 4. Kayu }
$$

Sumber: Dokumentasi Pribadi

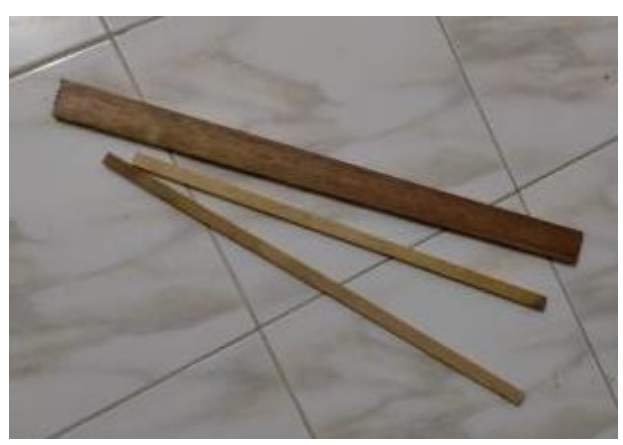

Kayu digunakan untuk bahan membuat produk karya seni lampu hiasan ruangan "Night Light Sadow Box". Kayu yang digunkan adalah kayu yang meiliki motif yang indah seperti kayu jati, pinus dll. selain indah juga harus memiliki ketahanan akan hewan atau cuaca dapat merusak karya tersebut.

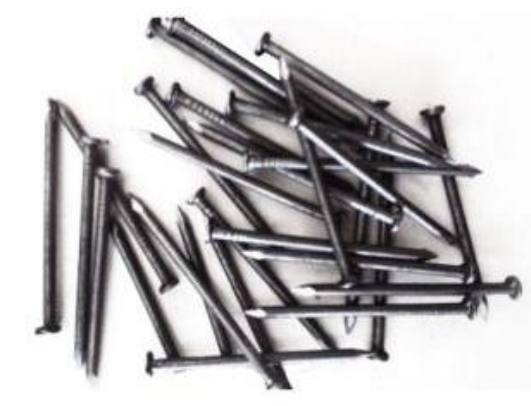

Gambar 5. Paku

Sumber: Dokumentasi Pribadi 
Paku untuk menyatukan kayu dalam produk karya seni lampu hiasan ruangan "Night Light Sadow Box".

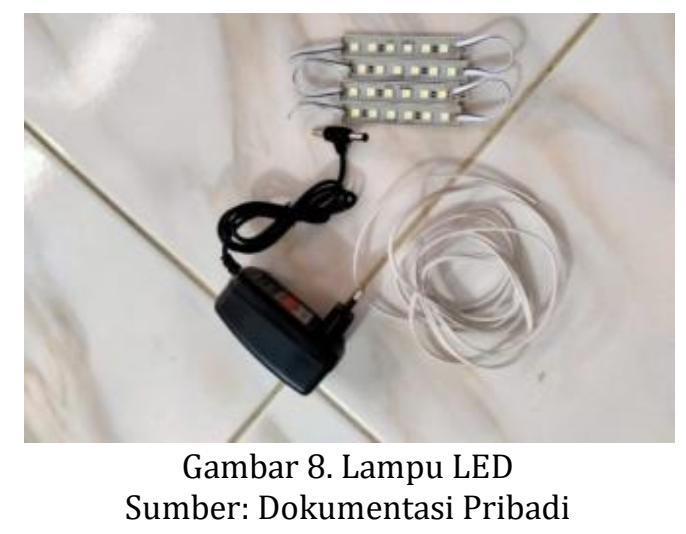

Lampu berfungsi untuk sumber pencahayaan produk karya seni lampu hiasan ruangan "Night Light Sadow Box". Lampu LED dipilih karena miliki pencahayaan yang terang dan hemat.



Gambar 9. Akrilik

Sumber: Dokumentasi Internet

Akrilik berfungsi untuk menjadi lapisan awal pada produk karya seni lampu hiasan ruangan "Night Light Sadow Box". Akrilik dipilih karena tidak mudah pecah dan ringan untuk dibawa.

\section{Observasi}

Tahap Observasi, pada tahap ini dilakukan pengkajian figure sebagai ide perancangan desain Lampu Hiasan Ruangan "Night Light Sadow Box". Tahap ini sangat penting dan diperlukan untuk mengobservasi sumber inpirasi dari figur yang akan di buat. Sehingga karya yang dibuat tidak menyimpang dari karakter Hanoman.

Studi lapangan yang dilakukan penulis selain melakukan tes adalah observasi berupa studi kepustakaan dan studi visual berupa karya dan benda-benda yang digunakan dalam karya lampu untuk penghias ruangan "Cahaya Malam Sadow Box". Observasi ini merupakan kegiatan merekam suatu gejala/kejadian dengan bantuan alat/alat untuk merekam/mencatatnya untuk kepentingan ilmiah atau tujuan lainnya. (Syamsudin, 2014). 
Observasi dalam karya ini adalah mengobservasi karakter figur dari Hanoman, melihat pose dan mencoba bagaimana jika karakter tersebut diterapkan dalam sebuah produk karya lampu hiasan ruangan "Night Light Sadow Box" yang bervisi budaya lokal ini. Observasi merupakan bagian dari upaya untuk mendorong penciptaan karya seni dan juga sebagai insentif untuk memicu kreativitas dalam proses penciptaan. (Apriyani, 2014).
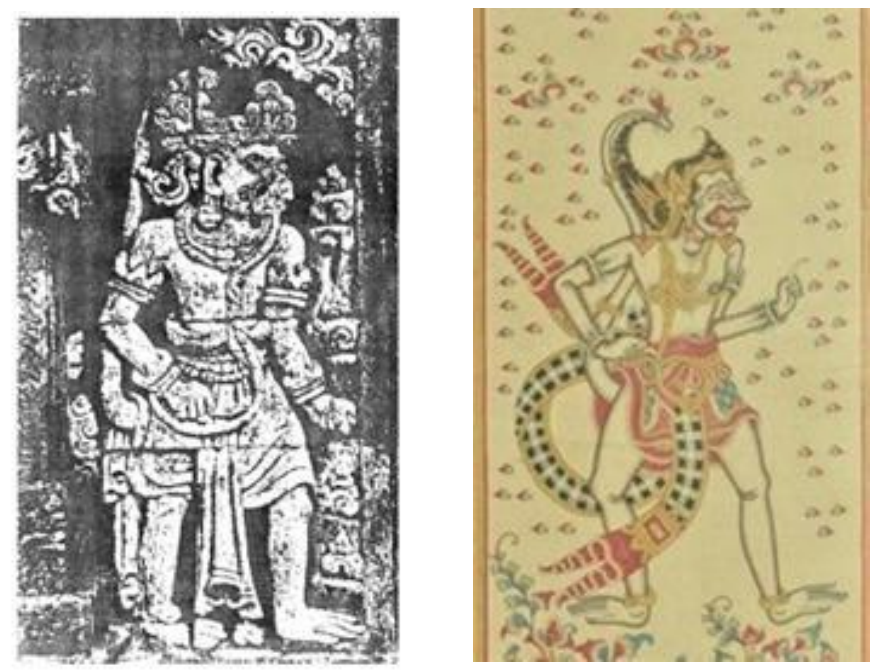

Gambar 2. Relief dan Lukisan Klasik Kamasan Bertema Hanoman Sumber: Dokumentasi Internet

\section{Desain Sketsa Terpilih}

Tahap Sketsa adalah proses sket gambar karakter hanoman menjadi desain awal perancangan. Sketsa dalam estetika Deleuzian adalah cikal bakal lukisan masa depan, yang disebut "diagram" (grafik). Inti dari diagram adalah "jejak" pelukis (guratan manual) yang menyertai proses bergambar (aksi menggambar).(Yangni, 2014). Kemudian pada sketsa dipertegas dengan garis outline untuk memudahkan proses pindai karya sketsa yang sudah jadi.
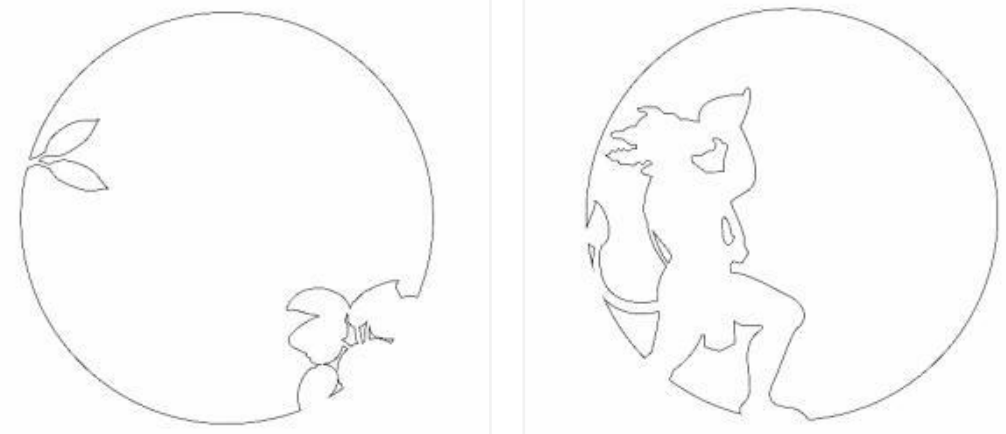

Gambar 3. Sket Rancangan Lampu Hiasan Ruangan “Night Light Sadow Box Sumber: Dokumentasi Pribadi 
Aqim Amral Hukmi, Hanoman Obong sebagai Ide Kreatif Penciptaan Night Light Shadow Box

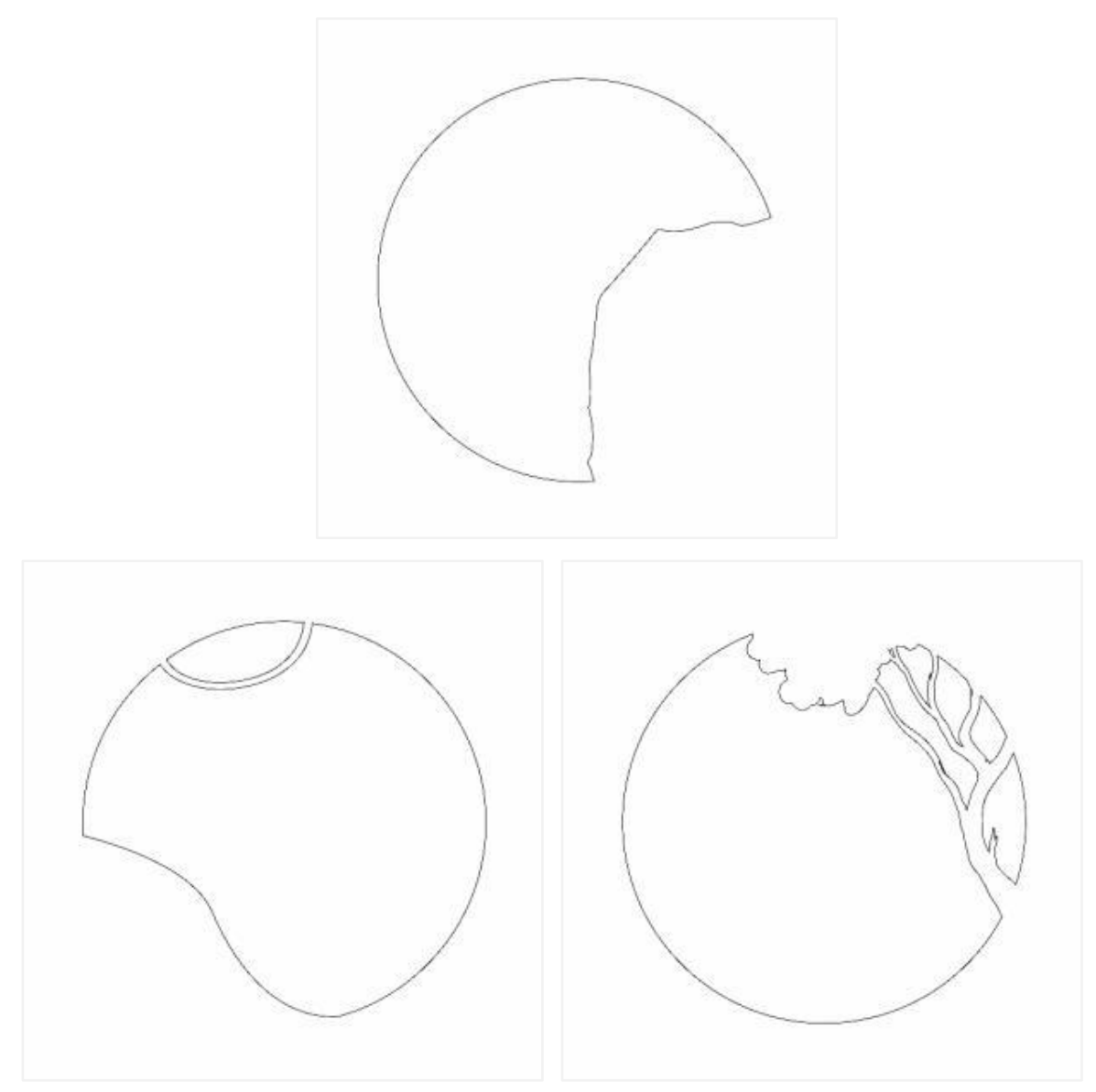

Gambar 4. Sket Rancangan Lampu Hiasan Ruangan "Night Light Sadow Box Sumber: Dokumentasi Pribadi

\section{Proses Cutting}

Tahap Cutting ini untuk memotong karya menyesuaikan bentuk desain yang telah ditentukan. Pada tahap memerlukan keterampilan dan ketekunan sehingga menghasilkan karya yang rapi dan indah.



Gambar 5. Proses Kerja Cutting

Sumber: Dokumentasi Pribadi 


\section{Proses Pembentukan Karya}

Tahap Pembuatan Karya adalah proses desain awal untuk menghasilkan karya yang sesuai dengan rancangan sket dan model Lampu Hiasan Ruangan "Night Light Sadow Box". Pada tahap ini adalah proses penyusunan sehingga karya tersebut dapat tertata dengan baik dan indah.
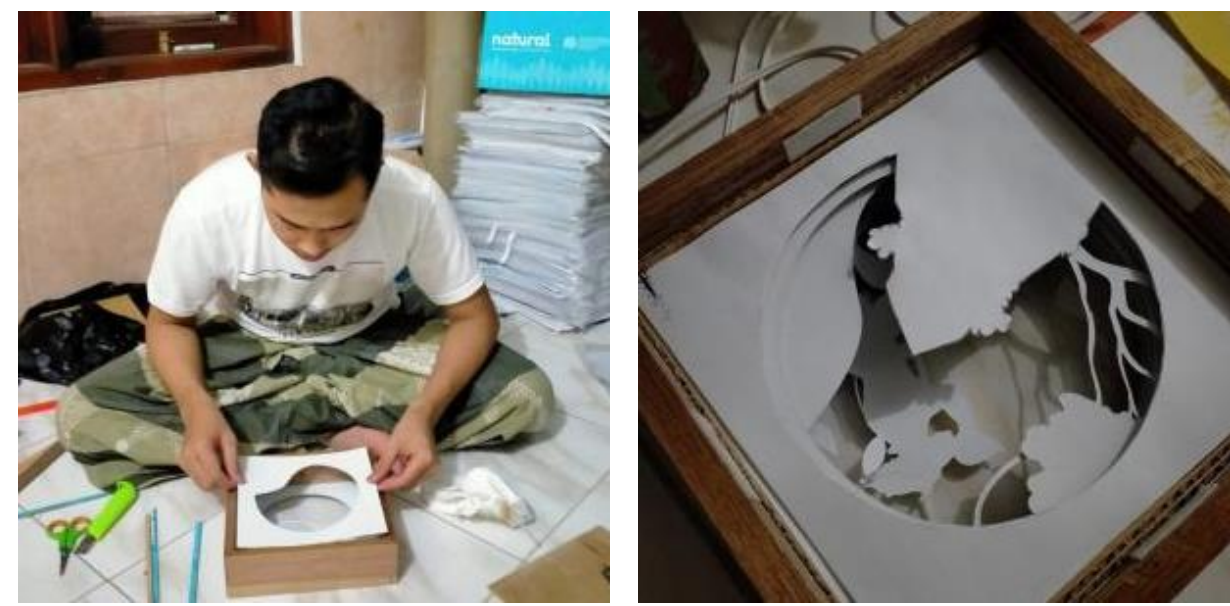

Gambar 6. Proses Kerja Penyusunan Poduk Karya Seni “Night Light Sadow Box Sumber: Dokumentasi Pribadi

\section{Hasil Visualisasi Karya (Publikasi)}

Berikut hasil visualisasi (Publikasi) ini adalah hasil final dalam berkarya Produk Karya Seni "Night Light Sadow Box" bervisi budaya lokal nusantara yang terinspirasi dari karakter figur Hanoman. Produk ini sangat cocok ditempatkan pada sudut ruangan sebagai dkorasi ruangan baik kantor, rumah, dll.
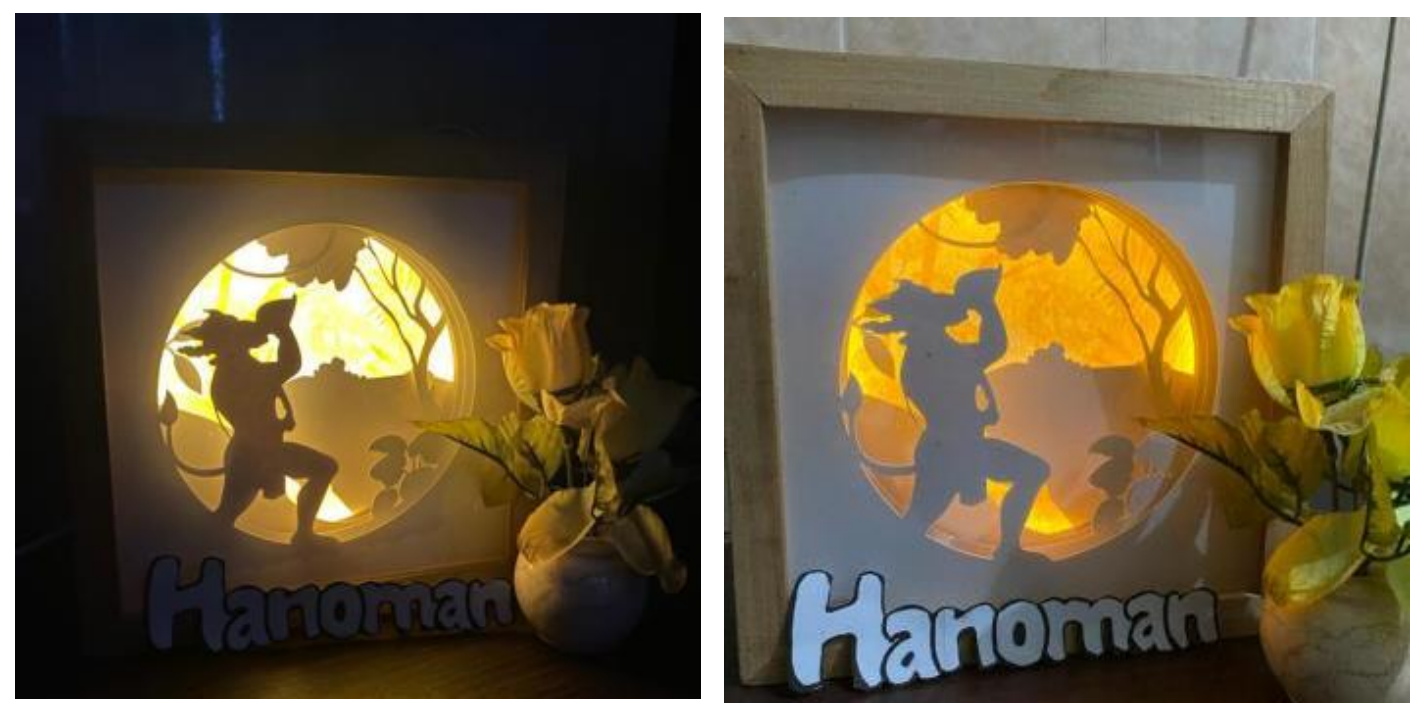

Gambar 7. Hasil Produk Karya Seni "Night Light Sadow Box" Sumber: Dokumentasi Pribadi

\section{SIMPULAN}

Berdasarkan penelitian yang telah dilakukan, dapat ditarik sebuah kesimpulan bahwa penciptaan sebuah poduk karya seni "Night Light Sadow Box" yang terinspirasi dari budaya lokal cerita pewayangan Hanoman yang terdapat pada sebuah relief candi, mampu menjadi sebuah inovasi baru dalam proses menyampaikan suatu wawasan pengetahuan kepada masyarakat luas sehingga mereka mencintai dan ikut melestarikan kebudayaan nusantara. Produk karya seni 
"Night Light Sadow Box" merupakan sebuah produk yang cocok dengan perkembangan zaman dan tetap bervisi budaya lokal nusantara, sekaligus mampu bersaing dengan produk-produk baru yang berasal dari bangsa asing.

\section{DAFTAR PUSTAKA}

Alif, M. Z., Savitri and Emilda, N. (2018) 'DESAIN CALONGCONG SEBAGAI UPAYA PELESTARIAN BUDAYA KERAJINAN TRADISIONAL', ATRAT, 6(2), pp. 197-200.

Andeska, N. (2018) 'Daun Sirih Merah sebagai Ide Penciptaan Kriya Kayu', Jurnal Warna, 2(1), pp. 30-38.

Apriyani, N. (2014) 'Objek Burung Hantu Sebagai Ide Gagasan Berkarya Tenun Tapestri', Universitas Pendidikan Indonesia, pp. 56-98.

Daniah (2016) 'KEARIFAN LOKAL (LOCAL WISDOM) SEBAGAI BASIS PENDIDIKAN KARAKTER', UIN Ar Raniry, p. 6.

Kristanto, A. (2017) 'Memahami Paradigma Pendidikan Seni', Jurnal Abdiel: Khazanah Pemikiran Teologi, Pendidikan Agama Kristen, dan Musik Gereja, 1(01), pp. 119-126. doi: 10.37368/ja.v1i01.90.

Mulyadika, V. S. and Lodra, I. N. (2018) 'KOMIK SI JUKI SEBAGAI IDE PENCIPTAAN SENI LUKIS', Jurnal Seni Rupa, 6(1), pp. 683-688.

Njatrijani, R. (2018) 'Kearifan Lokal Dalam Perspektif Budaya Kota Semarang Gema Keadilan Edisi Jurnal Gema Keadilan Edisi Jurnal', Gema Keadilan Edisi Jurnal 17, 5(September), pp. 16-31.

Noor, J. (2015) METODOLOGI PENELITIAN: SKRIPSI, TESIS, DISERTASI, DAN KARYA ILMIAH. 5th edn. Jakarta: PRENADAMEDIA GRUB.

Sebastian, T. et al. (2017) 'Perancangan Permainan Kartu Sebagai Media Pengenalan Tokoh Pewayangan Dengan Basis Kisah Ramayana', www.neliti.com, pp. 1-12.

Solichudin, R. M. (2016) PEMBUATAN PERMAINAN EDUKASI TIGA DIMENSI " ANOMAN OBONG" MENGGUNAKAN APLIKASI BLENDER MEDIA THE DEVELOPMENT OF 3D GAME " ANOMAN OBONG" USING BLENDER AS A LEARNING MEDIA OF TRADITIONAL. ITS (Institut Teknologi Sepuluh Nopember).

Subandi, P. E. S. (2017) ‘UPT Perpustakaan ISI Yogyakarta UPT Perpustakaan ISI Yogyakarta', Computers in Human Behavior, 63(May), pp. 9-57.

Syamsudin, A. (2014) '2882-8276-1-PB (1).pdf', p. 413.

Wulandari, S. and Siregar, E. D. (2020) 'Titian: Jurnal Ilmu Humaniora Vol. 04, No. 1, Juni 2020', TITIAN : Jurnal Ilmu Humaniora, 04(1), pp. 29-41.

Yangni, S. (2014) Sketsa sebagai Proses Kreatif dalam Seni Lukis. ISI YOGYAKARTA.

Yusa, I. M. M. (2016) 'Literasi Visual Tokoh Hanoman Bali dengan Pendekatan Augmented Reality', Journal Studi Kultural, II(1), pp. 42-47. 